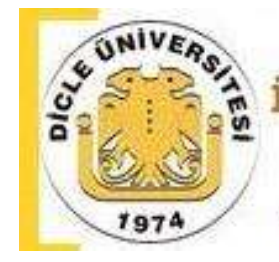

Yıl / Year: 2021

Araştırma Makalesi

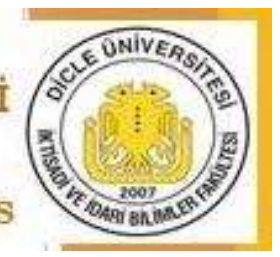

Cilt / Volume: $11 \quad$ Sayı / Issue: 21

Sayfalar / Pages: 73-84

Kabul Tarihi: 09.03.2021

\title{
KAMU SAĞLIK HARCAMASININ ÜÇ TEMEL SAĞLIK GÖSTERGESİNE ETKİSİ: OECD ÜLKELERİ ÜZERİNE BİR PANEL REGRESYON ANALİŻ
}

Fatih ŞANTAŞ ${ }^{1}$

Gülcan ŞANTAŞ ${ }^{2}$

Bünyamin DEMIRGIL ${ }^{3}$

\section{$\ddot{O} z$}

$\mathrm{Bu}$ çalışmada, kamu sağlık harcamasının sağlık sonuçları üzerindeki etkisinin araştırılması amaçlanmaktadır. Çalışma kapsamında, sağlık sonuçları olarak OECD ülkelerinin 2000-2017 dönemine ait bebek ölüm hızı, anne ölüm oranı ve doğumda beklenen yaşam süresi değişkenleri kullanılmıştır. Sağlık harcamalarının bebek ölüm hızı, anne ölüm hızı ve doğumda beklenen yaşam süresi üzerindeki etkisini araştırmak için oluşturulan üç model panel regresyon analizi ile incelenmiştir. Gerçekleştirilen panel regresyon analizi sonuçlarına göre bebek ölüm hızındaki değişimin \%79'u, anne ölüm oranındaki değişimin \%74'ü ve doğumda beklenen yaşam süresindeki değişimin \%84'ü kamu sağlık harcaması tarafından açıklanmaktadır. Analizler, OECD ülkelerinde kamu sağlık harcamalarında meydana gelen artışın bebek ölüm hızı ve anne ölüm oranını düşürürken doğumda beklenen yaşam süresini artırdığını göstermektedir. Çalışma sonucunda verimlilik ve etkililik gibi prensiplerin de dikkate alınarak kamu sağlık harcamasının artırılması önerilmektedir.

Anahtar Kelimeler: Kamu Sağlık Harcaması, Sağlık Göstergeleri, OECD Ülkeleri.

Jel Kodları: H51, I10, I18.

${ }^{1}$ Doç. Dr., Yozgat Bozok Üniversitesi İİF Sağlık Yönetimi Bölümü, Yozgat/Türkiye, E-posta: fatih.santas@bozok.edu.tr, ORCID: 0000-0002-1243-8275.

${ }^{2}$ Dr. Öğr. Üyesi, Yozgat Bozok Üniversitesi İIBF Sağlı Yönetimi Bölümü, E-posta: gulcan.santas@bozok.edu.tr, ORCID: 0000-0002-0488-9375.

${ }^{3}$ Dr. Öğr. Üyesi, Sivas Cumhuriyet Üniversitesi İIBF Maliye Bölümü, E-posta: bdemirgil@cumhuriyet.edu.tr, ORCID: 0000-0002-1150-0225.

\section{Atıf/Citation}

Şantaş, F., Şantaş, G. ve Demirgil, B. (2021), "Kamu Sağlık Harcamasının Üç Temel Sağlık Göstergesine Etkisi: OECD Ülkeleri Üzerine Bir Panel Regresyon Analizi”, Dicle Üniversitesi İktisadi ve İdari Bilimler Fakültesi Dergisi, 11(21), s.73-84. 


\title{
THE EFFECT OF PUBLIC HEALTH EXPENDITURE ON THREE MAIN HEALTH INDICATORS: A PANEL REGRESSION ANALYSIS ON OECD COUNTRIES
}

\begin{abstract}
In this study, it is aimed to investigate the effect of public health expenditure on health outcomes. In the scope of the study, the variables of infant mortality rate, maternal mortality rate and life expectancy at birth for the period 2000-2017 of OECD countries were used as health outcomes. Three models created to investigate the effect of health expenditures on infant mortality rate, maternal mortality rate and life expectancy at birth were examined by panel regression analysis. According to the results of the panel regression analysis, $79 \%$ of the change in infant mortality rate, $74 \%$ of the change in maternal mortality rate and $84 \%$ of the change in life expectancy at birth are explained by public health expenditures. Analyzes demonstrate that the increase in public health expenditures in OECD countries decreased infant mortality rate and maternal mortality, while increasing life expectancy at birth. As a result of the study, it is recommended to increase public health expenditures by taking into account principles such as efficiency and effectiveness.
\end{abstract}

Key Words: Public Health Expenditure, Health Indicators, OECD Countries.

Jel Codes: H51, I10, I18.

\section{GíRIŞ}

Birey ve her düzeydeki sağlık yöneticisinin en temel amaçları arasında sağlıklı birey ve toplum yer almaktadır. Bilindiği gibi sağlı̆̆ı etkileyen çok sayıda etmen bulunmaktadır ve bu etmenler literatürde sağlığın belirleyicileri olarak ifade edilmektedir. Sağlık hizmeti, sağlığın belirleyicileri diğer bir ifadeyle sağlığı etkileyen faktörler arasında yer almaktadır. Sağlık hizmeti için finansal kaynağa ihtiyaç duyulmaktadır ve sağlık hizmeti için yapılan harcamalar, sağlık harcamaları olarak adlandırılmaktadır.

Sağlık hizmeti için hem devletler hem de bireyler harcama yapmaktadır. Ancak sağlık harcamasının oranının ne olması gerektiğinin kesin cevabı bulunmamaktadır. Bu hususa ilişkin dört yaklaşım vardır. Bunlar; benzer ülkeler yaklaşımı, politik ekonomi yaklaşımı, üretim fonksiyonu yaklaşımı ve bütçe yaklaşımı. Benzer ülkeler yaklaşımında sağlık, kültür gibi benzer göstergelere sahip olan ülkenin harcadığı miktar kadar harcama yapılması gerektiği ifade edilmektedir. Politik ekonomi yaklaşımında ne kadar harcama yapılmalı sorusundan ziyade neden daha az ya da daha fazla harcama yapılmalı sorusuna yanıt aranmaktadır. Üretim fonksiyonu yaklaşımında girdi-çıktı ilişkisinden yola çıkılarak sağlık girdileri ile sağlık çıktıları arasındaki en uygun bileşim doğrultusunda uygun kaynak miktarı belirlenmeye çalışılmaktadır. Bütçe yaklaşımında ise ne kadar kaynak ayrılması gerektiğine mecliste bir bütçe dâhilinde karar verilmektedir (Çelik, 2019: 312). Sağlık harcaması miktarı 
belirlenirken bu dört yaklaşımdan biri kullanılabileceği gibi yaklaşımların tamamından da yararlanmak mümkündür.

Sağlık harcamaları çeşitli türlere ayrılmaktadır. Sağlık harcamaları; hizmet sunucularına, fonksiyonlarına, niteliklerine, finansmanı sağlayanlara (kamu-özel) göre sınıflandırılabilmektedir (Ağır ve Tıraş, 2018: 646). Kamu sağlık harcaması, devlet bütçesi tarafından yapılan harcamaları ifade ederken; özel sağlık harcamaları ise sağlık hizmeti finansmanının doğrudan ya da dolaylı olarak bireylerin (vatandaşların) yaptı̆̆ harcamaları ifade etmektedir. Sağlık harcamasının ne kadar olması gerektiğine ilişkin fikir birliği olmadığı gibi ülkelerde kamu ya da özel harcamaların oranının ya da ağırlığının ne kadar olması gerektiğine ilişkin de fikir birliği bulunmamaktadır. Ancak bilinen husus, sağlık hizmetinin talep esnekliğinin katı olması nedeniyle bir diğer ifadeyle fiyatı ne olursa olsun çoğu sağlık hizmetine talebin zorunlu olması nedeniyle başta Dünya Sağlık Örgütü (DSÖ) olmak üzere çeşitli otoriteler ve araştırmalar sağlık harcamalarında özel sağlık harcamasının ve özel sağlık harcamasının türü olan cepten sağlık harcamasının ağırlığının çok yüksek olmamasını önermektedirler. $\mathrm{Bu}$ doğrultuda cepten sağlık harcamaları ülkelerin sağlık sistemleri performanslarının değerlendirilmesinde bir ölçüt olarak kullanılmaktadır. Cepten sağlık harcamalarının yüksekliğinin hane ve bireyler için yıkıcı (katastrofik) harcama özelliği haline gelmemesi için kamu sağlık harcamalarının ağırlığı önem taşımaktadır.

Şekil 1'de OECD ülkelerinde toplam kamu sağlı harcamasının GSYH'ye oranı verilmektedir. ABD \%14,42 ile ilk sırada yer alırken, Türkiye'de oran \%3,28'dir.

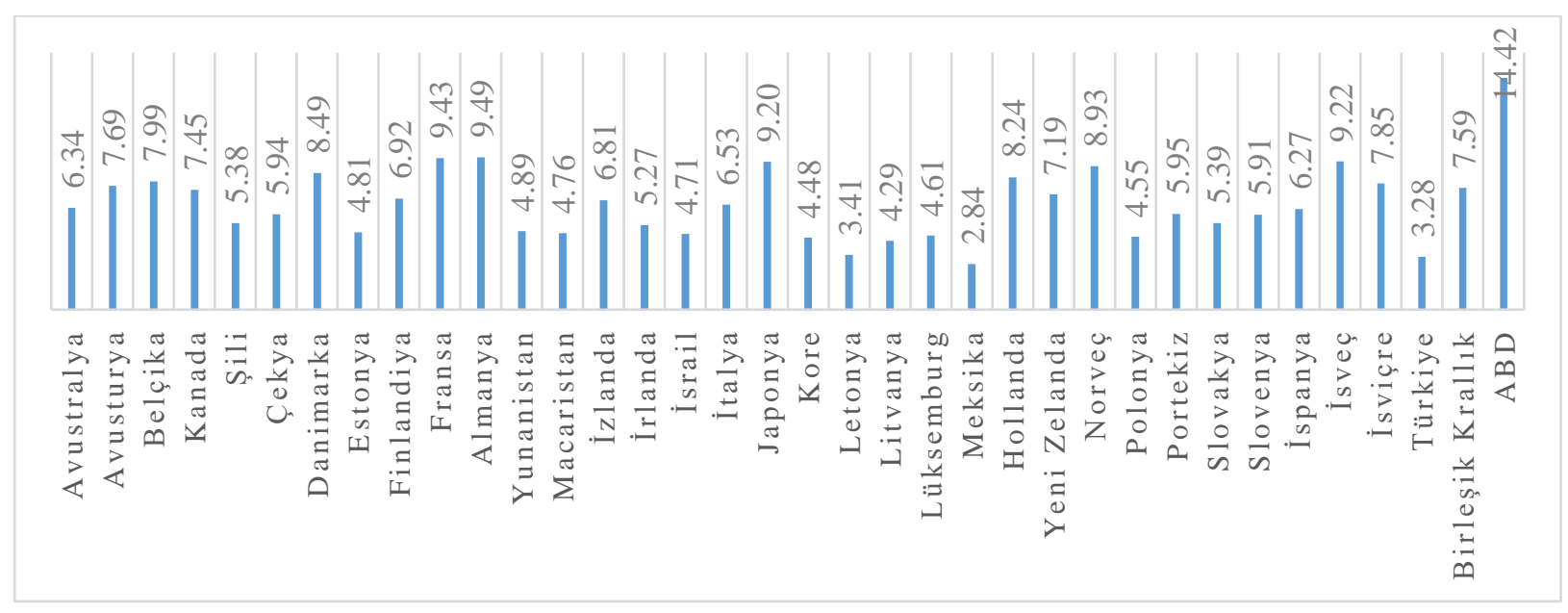

Şekil 1. OECD Ülkeleri Toplam Kamu Sağlık Harcamasının GSYH'ye Oranı (\%) 
Kaynak: Sağlık Bakanlığg (2019). Sağlık istatistikleri yıllığı 2018, Ankara: Sağlık Bilgi Sistemleri Genel Müdürlüğü, Erişim Linki: https://dosyasb.saglik.gov.tr/eklenti/36134,siy2018trpdf.pdf?0, Erişim Tarihi: 15.08.2020.

Çalışmanın sağlık sonuçları olarak incelenen ve ülke sağlık sistemlerinin başarısını gösteren değişkenlerden birisi, bebek ölüm hızıdır. Bebek ölüm hızı, sağlık sistemlerinin performansı yanında ülkelerin gelişmişlikleri hakkında da bilgi vermektedir. Bunun nedeni bebek ölümünün sağlık sistemi ve sağlık hizmeti dışında eğitim, çevre koşulları, hane koşulları, gelir, yaşanan bölge, yerleşim yeri (kent/kır) gibi faktörlerden de etkilenmesidir. Ayrıca bebek ölüm hızı, ülkedeki ana-çocuk sağlığının da önemli bir göstergesidir. Bebek ölüm hızı, bir toplumda canlı doğup bir yaşını tamamlamadan ölen bebek sayısının aynı toplum ve aynı süredeki canlı doğum sayısına oranlanması ile hesaplanmaktadır (Sümbüloğlu, 1990; Tezcan, 2009; Karagöz, 2014; Çelik, 2019).

Şekil 2'de bebek ölüm hızının uluslararası karşılaştırması verilmektedir. Bebek ölüm hızı Dünya'da \%o 28,9 iken OECD ülkeleri için ise \%o 5,5'tir. Türkiye \%o 9,2 oranı ile DSÖ Avrupa Bölgesi, OECD ülkeleri, üst gelir grubu ülkeleri ve $\mathrm{AB}$ ülkeleri ortalamasının üzerinde yer almaktadır.

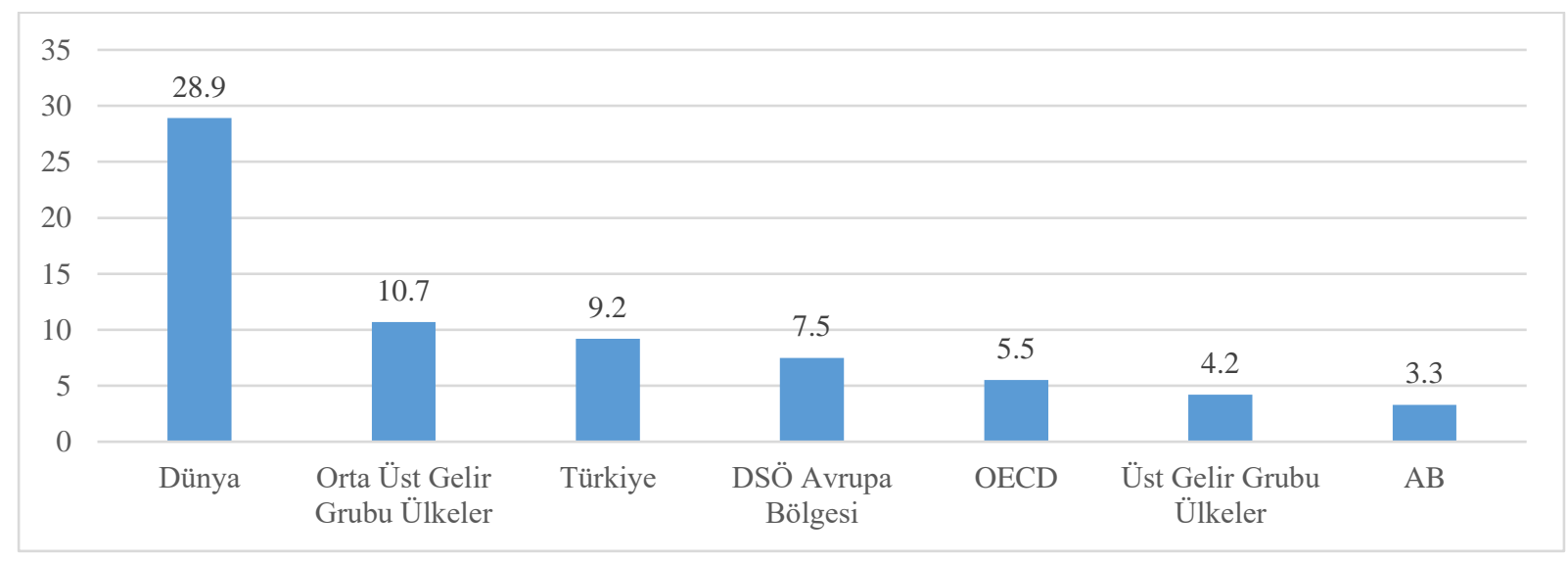

Şekil 2. Bebek Ölüm Hızının Uluslararası Karşılaştırması, (1.000 Canlı Doğumda)

Kaynak: Sağlık Bakanlığı (2019). Sağlık istatistikleri yıllığı 2018, Ankara: Sağlık Bilgi Sistemleri Genel Müdürlüğü, Erişim Linki: https://dosyasb.saglik.gov.tr/Eklenti/36134,siy2018trpdf.pdf?0, Erişim Tarihi: 15.08.2020.

Anne ölüm oranı, temel sağlık sonucu olarak değerlendirilen ve ülke sağlık sistemi performanslarının karşılaştırılması ve yeterliliğinin izlenmesinde yararlanılan göstergeler arasındadır. Ölümlerin anne ölümü olarak değerlendirilmesi için ölümün gebelik ve doğumla ilgili olması gerekmektedir. Kaza, intihar ya da herhangi bir sebeple gerçekleşen ölümler anne 
ölümüne dâhil edilmemektedir. Anne ölüm oranı, gebelik ya da doğum sebebiyle ölen kadın sayısının canlı doğan bebek sayısına oranlanması ile hesaplanmaktadır. Anne ölüm oranının birimi, yüz bindir (Sümbüloğlu, 1990; Tezcan, 2009; Karagöz, 2014; Çelik, 2019).

Anne ölüm oranının uluslararası karşılaştırması Şekil 3'te verilmektedir. Şekil 3 incelendiğinde anne ölüm oranı en fazla yüz binde 211 ile Dünya genelinde, en az ise yüz binde 6 ile AB ülkelerindedir. Türkiye'de anne ölüm oranı yüz binde 13,6'dır.

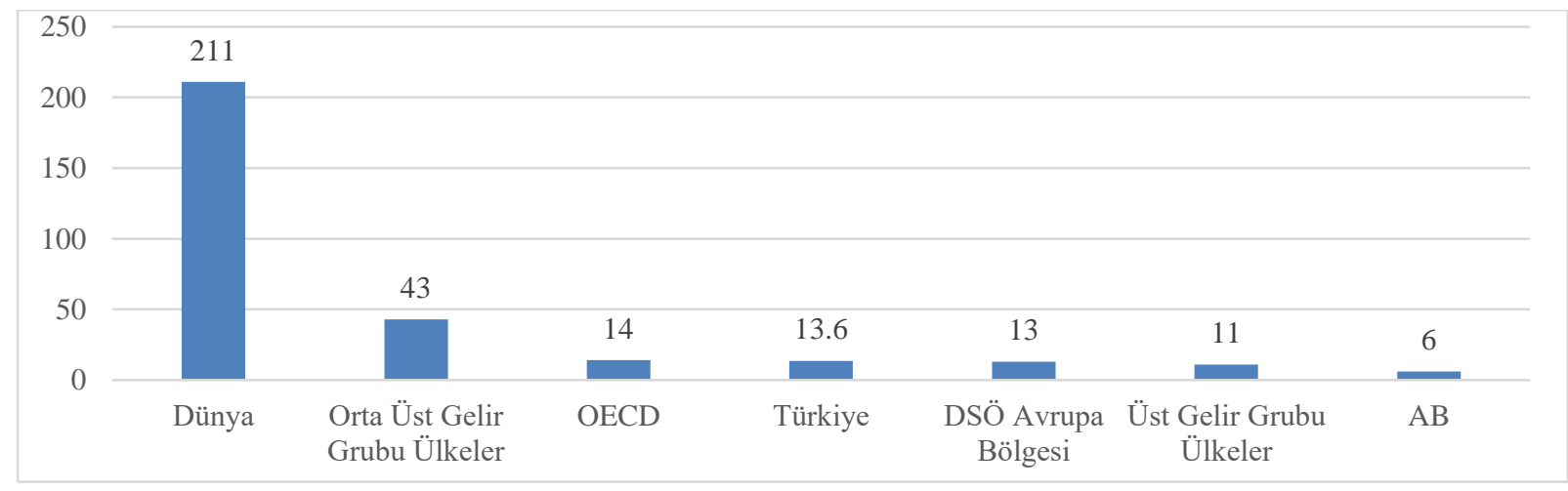

Şekil 3. Anne Ölüm Oranının Uluslararası Karşılaştırması, (100.000 Canlı Doğumda)

Kaynak: Sağlık Bakanlığı (2019). Sağlık istatistikleri yıllığı 2018, Ankara: Sağlık Bilgi Sistemleri Genel Müdürlüğü, Erişim Linki: https://dosyasb.saglik.gov.tr/Eklenti/36134,siy2018trpdf.pdf?0, Erişim Tarihi: 15.08.2020.

Çalışmanın bir diğer sağlık değişkeni doğumda beklenen yaşam süresidir. Doğumda beklenen yaşam süresi (DBYS), ülkeler geliştikçe artmaktadır ve bir kişinin ortalama kaç yı1 yaşayacağını gösteren ölçüttür. Ortalama bir ölçüt olup, herhangi bir birey ülke DBYS rakamından daha fazla ya da daha az yaşayabilir. Ayrıca DBYS, kadın ve erkekler için farklıdır ve genellikle kadınlarda DBYS daha fazladır. DBYS'ye çeşitli faktörler etki etmekte olup, Bayın (2016) tarafından yapılan çalışmada DBYS'ye etki eden en önemli faktörün bebek ölüm hızı olduğu tespit edilmiştir.

Şekil 4'te doğumda beklenen yaşam süresi verilmektedir. DBYS, OECD ve AB ülkelerinde 80 yıl civarında iken Türkiye'de ise 78,3 yıldır. Türkiye'de DBYS; DSÖ Avrupa Bölgesi, orta üst gelir grubu ülkeler ve dünya ortalamasından fazladır. 


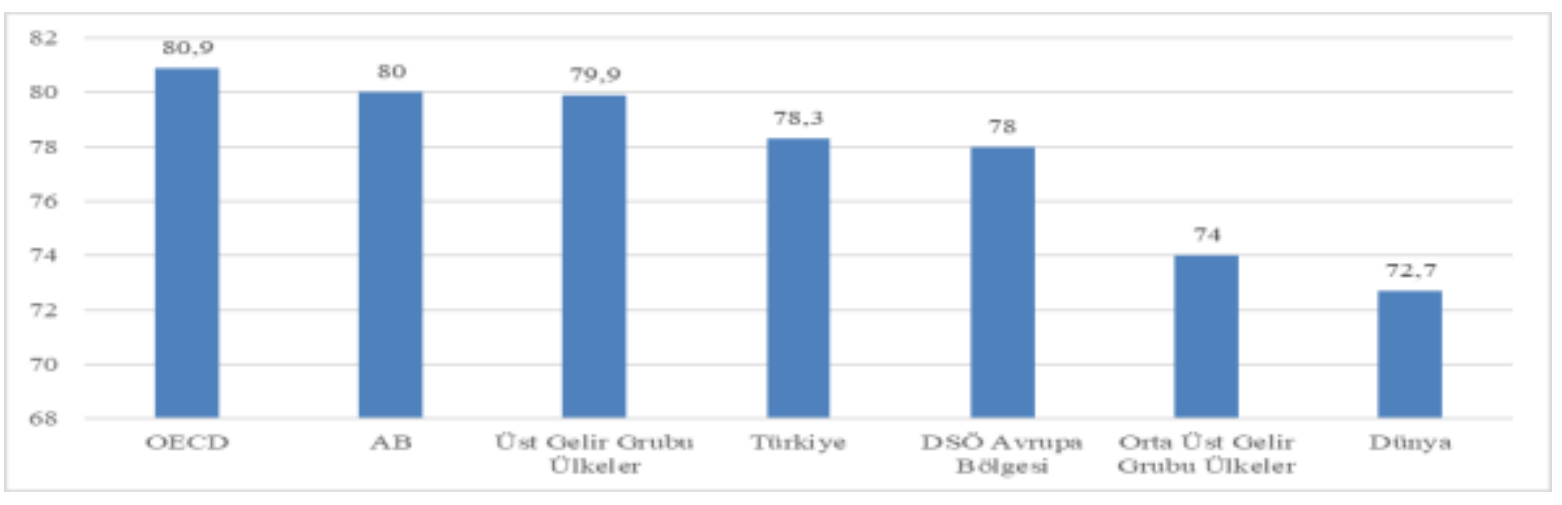

Şekil 4. Doğumda Beklenen Yaşam Süresinin Uluslararası Karşılaştırması, (Y11)

Kaynak: Sağlık Bakanlığı (2019). Sağlık istatistikleri yıllığı 2018, Ankara: Sağlık Bilgi Sistemleri Genel Müdürlüğü, Erişim Linki: https://dosyasb.saglik.gov.tr/Eklenti/36134,siy2018trpdf.pdf?0, Erişim Tarihi: 15.08.2020.

\section{YÖNTEM}

$\mathrm{Bu}$ çalışma, kamu sağlık harcamasının sağlık sonuçları üzerindeki etkisi OECD ülkeleri ve 2000-2017 dönemi için panel regresyon analizi ile araştırılması amacıyla gerçekleştirilmiştir. Çalışmada sağlık sonuçları olarak bebek ölüm hızı, anne ölüm hızı ve doğumda beklenen yaşam süresi değişkenleri kullanılmıştır.

$\mathrm{Bu}$ çalışmanın 2000 yılından günümüze OECD ülkelerini kapsaması ve kamu sağlık harcamalarını odağına alması (genel sağlık harcaması ya da kişi başına sağlık harcamasını inceleyen çeşitli çalışmalar bulunmaktadır) ve üç temel sağlık değişkenini incelemesi nedeniyle ilgili literatüre katkı sağlayacağı düşünülmektedir. Çalışmada özellikle kamu sağlık harcamasının seçilmesinin nedeni hemen hemen her ülkede sağlık harcaması artmakla birlikte bu artışta cepten sağlık harcamasındaki artışın da etkisinin olması ve cepten sağlık harcamasındaki artışın hem yıkıcı etkilerinin olması hem de kamu sağlık harcamaları gibi tüm topluma yayılan faydasının olamaması durumlarıdır.

Çalışmada kullanılan değişkenler, Tablo 1'de yer almaktadır.

Tablo 1. Çalışmada Kullanılan Değişkenler

\begin{tabular}{|l|l|c|}
\hline Kısaltmalar & \multicolumn{1}{|c|}{ Değişkenler } & Kaynak \\
\hline KSH & $\begin{array}{l}\text { Kamu Sağlık Harcaması (Toplam Kamu Sağlık } \\
\text { Harcamasının GSYH'ye Oranı, \%) }\end{array}$ & OECD \\
\hline BÖH & Bebek Ölüm Hızı (Binde) & WHO \\
\hline AÖO & Anne Ölüm Oranı (Yüz Binde) & WHO \\
\hline DBYS & Doğumda Beklenen Yaşam Süresi (Yıl) & WHO \\
\hline
\end{tabular}


Çalışmada kamu sağlık harcamalarının sağlık sonuçları değişkenleri olarak alınan bebek ölüm hızı, anne ölüm hızı ve doğumda beklenen yaşam süresi üzerindeki etkisini araştırmak için kamu sağlık harcamasının bağımsız değişken olarak alındığı üç model oluşturulmuştur:

Model I: $\mathrm{BÖH}=\beta_{0}+\beta_{1} \mathrm{KSH}+\mathrm{ut}$

Model II: AÖO $=\beta_{0}+\beta_{1} \mathrm{KSH}+\mathrm{ut}$

Model III: DBYS $=\beta_{0}+\beta_{1} \mathrm{KSH}+\mathrm{ut}$

\section{BULGULAR}

Çalışmada regresyon analizine başlamadan önce modellerde kullanılacak değişkenlerin durağanlığı sınanmıştır. Bu kapsamda Levin, Lin ve Chu (LLC) birim kök testi kullanılmıştır. Değişkenlere ilişskin LLC birim kök testi sonuçları Tablo 2'de yer almaktadır. Tablo 2'de yer alan değişkenlere ait LLC birim kök testi sonuçlarına göre çalışmada kullanılan tüm değişkenlerin durağan oldukları görülmektedir.

Tablo 2. LLC Panel Birim Kök Testi Sonuçları

\begin{tabular}{|l|c|c|}
\hline Değişkenler & İstatistik Değeri & Olasıllk Değeri \\
\hline KSH & -272.665 & 0.0032 \\
\hline BÖH & -113.048 & 0.0000 \\
\hline AÖO & -101.629 & 0.0000 \\
\hline DBYS & -112.672 & 0.0000 \\
\hline
\end{tabular}

Çalışmada havuzlanmış (klasik) model ile sabit etkiler modeli arasında uygun modelin hangisinin olduğunu tespit etmek için F testi uygulanmıştır. F testi için oluşturulan hipotezler şu şekildedir:

$\mathrm{H}_{0}$ : Havuzlanmış regresyon modeli uygundur.

$\mathrm{H}_{1}$ : Sabit etkiler modeli uygundur.

Tablo 3. F Testi Sonuçları

\begin{tabular}{|l|c|c|}
\hline Modeller & F İstatistiği & Olasilık \\
\hline Model 1 & 205.0521 & 0.0000 \\
\hline Model 2 & 217.5542 & 0.0000 \\
\hline Model 3 & 381.2588 & 0.0000 \\
\hline
\end{tabular}

Tablo 3'te yer alan F testi sonuçlarına göre tüm modellerde olasılık değerleri 0,05'ten küçük olduğundan $\mathrm{H}_{0}$ hipotezi reddedilmekte ve $\mathrm{H}_{1}$ hipotezi kabul edilmektedir. Buna göre sabit etkiler modeli ile tahmin yapılması uygundur. F testi sonrası panel veri analizinde regresyon 
modelinin sabit veya rassal etki modellerinden hangisinin uygulanacağının belirlenmesi için Hausman testi yapılmıştır. Hausman testi için oluşturulan hipotezler şu şekildedir:

$\mathrm{H}_{0}$ : Rassal etkiler modeli uygundur.

$\mathrm{H}_{1}$ : Sabit etkiler modeli uygundur.

Tablo 4. Hausman Testi Sonuçları

\begin{tabular}{|l|c|c|}
\hline Modeller & F İstatistiği & Olasılık \\
\hline Model 1 & 5.159 .486 & 0.0231 \\
\hline Model 2 & 7.605 .490 & 0.0058 \\
\hline Model 3 & 3.880 .838 & 0.0488 \\
\hline
\end{tabular}

Tablo 4'te yer alan Hausman testi sonuçlarına göre tüm modellerde olasılık değerleri 0,05'ten küçük olduğu için $\mathrm{H}_{0}$ hipotezi reddedilmekte ve $\mathrm{H}_{1}$ hipotezi kabul edilmektedir. Buna göre sabit etkiler modeli ile tahmin yapılması uygundur. Kamu sağlık harcamalarının sağlık sonuçları üzerindeki etkisinin tespitine yönelik oluşturulan üç modele ilişkin sabit etkilere göre yapılan panel regresyon analizi sonuçları Tablo 5'te yer almaktadır.

Tablo 5. Panel Regresyon Analizi Sonuçları

\begin{tabular}{|c|c|c|c|c|c|}
\hline $\begin{array}{l}\text { Bağımlı } \\
\text { Değişken }\end{array}$ & Bağımsız Değişken & Katsayı & Standart Hata & İstatistik & Olasılık \\
\hline \multirow{4}{*}{$\begin{array}{c}\text { Bebek Ölüm } \\
\text { Hızı }\end{array}$} & \multicolumn{5}{|c|}{ MODEL I } \\
\hline & Sabit & 7.648017 & 0.487775 & 1.56 & 0.000 \\
\hline & $\begin{array}{l}\text { Kamu Sağlık } \\
\text { Harcaması }\end{array}$ & -0.454853 & 0.080172 & -5.67 & 0.000 \\
\hline & $\mathrm{R}^{2}=0.79$ & \multicolumn{2}{|c|}{ Olas1lık $>\mathrm{F}=0.000$} & \multicolumn{2}{|c|}{ Gözlem = 641} \\
\hline \multirow{4}{*}{$\begin{array}{c}\text { Anne Ölüm } \\
\text { Oranı }\end{array}$} & \multicolumn{5}{|c|}{ MODEL II } \\
\hline & Sabit & 1.541245 & 2.074490 & 7.42 & 0.000 \\
\hline & $\begin{array}{l}\text { Kamu Sağlık } \\
\text { Harcaması }\end{array}$ & -1.073731 & 0.350632 & -3.06 & 0.002 \\
\hline & $\mathrm{R}^{2}=0.74$ & Olas1lik $>\mathrm{F}=$ & Grup $=$ & Göz & 641 \\
\hline & & & IODEL III & & \\
\hline Doğumda & Sabit & 7.440431 & 0.360239 & 2.06 & 0.000 \\
\hline Yaşam & $\begin{array}{l}\text { Kamu Sağlık } \\
\text { Harcaması }\end{array}$ & 0.757309 & 0.059284 & 1.27 & 0.000 \\
\hline Suress & $\mathrm{R}^{2}=0.84$ & Olasılık $>\mathrm{F}$ & Grup = & Göz & 641 \\
\hline
\end{tabular}


Tablo 5'te kamu sağlık harcamalarının sağlık sonuçları üzerindeki etkisinin tespiti için oluşturulan üç modelden birincisinde kamu sağlık harcamaları ile bebek ölüm hızları arasında istatiksel olarak anlamlı ve negatif bir ilişki bulunmaktadır. Benzer ilişki kamu sağlık harcamaları ile anne ölüm hızları arasında kurulan ikinci model için de geçerlidir. Üçüncü modelde ise kamu sağlı harcamaları ile doğumda beklenen yaşam süresi arasında istatiksel olarak anlamlı ve pozitif bir ilişki bulunmaktadır. Tüm modellerin regresyon analizi sonuçları birlikte değerlendirildiğinde OECD ülkelerinde kamu sağlık harcamalarında meydana gelen artış bebek ölüm hızları ve anne ölüm hızlarını düşürürken doğumda beklenen yaşam süresini artırmaktadır.

\section{SONUÇ VE ÖNERILER}

Bu çalışmada kamu sağlık harcamalarının ülke sağlık sistemlerinin değerlendirilmesinde en fazla kullanılan sağlı göstergeleri olan bebek ölüm hızı, anne ölüm oranı ve doğumda beklenen yaşam süresine etkisi araştırılmıştır. Çalışma, OECD ülkelerini ve 2000-2017 dönemini kapsamaktadır. Çalışmada panel regresyon analizi kullanılmıştır. Çalışmanın bulguları ve bulgulara yönelik değerlendirmeler şu şekildedir:

Çalışmanın analizleri kamu sağlık harcamasının bebek ölüm hızını azaltıcı bir etki yaptığını göstermektedir. Gerçekleştirilen panel regresyon analizi sonucuna göre bebek ölümündeki değişimin \%79’u kamu sağlık harcaması tarafından açıklanmaktadır. Bu sonuç, kamu sağlık harcamasının artmasının bebek ölümünde azaltıcı bir etki yapacağı şeklinde yorumlanabilir. Barenberg vd. (2017) tarafından gerçekleştirilen ve bebek ölümü üzerinde politik hususlar, kişi başına gelir, kadın okuryazarlığı ve kentleşme gibi faktörlerin etkisi sabitlendikten sonra yapılan panel veri analizinde kamu sağlık harcamasının bebek ölümünü azalttığı belirlenmiştir. Kiross vd. (2020) tarafindan 46 Sahra Altı Afrika ülkesini ve 2000-2015 kapsayan çalışmada kamu sağlık harcamasının bebek ölümünü azaltıcı etkisi olduğu belirlenmiştir. Çalışmada bebek ölümü üzerinde özel sağlık harcamasının etkisinin olmadığı belirlenmiştir. Alanyazında genel sağlık harcamasındaki artışın da bebek ölümünü azalttığı belirlenmiştir. Tüylüoğlu ve Tekin (2009) tarafından yapılan çalışma sonucunda kişi başına sağlık harcamasındaki artışın bebek ölümünü azalttı̆̆ bulgusuna ulaşılmıştır.

Çalışmada kamu sağlık harcamasının anne ölüm oranı üzerindeki etkisine ilişkin gerçekleştirilen analiz sonuçlarına bakıldığında bebek ölüm hızında olduğu gibi kamu sağlık harcamasının anne ölüm oranını azaltıcı bir etki oluşturduğu görülmektedir. Bağımsız değiş̧ken (kamu sağlık harcaması) bağımlı değişkendeki (anne ölüm oranı) değişimin 
\%74'ünü açıklamaktadır. Bu bulgu, Nwankwo (2018) tarafından Nijerya'da 2003-2015 yıllarını analiz kapsamına alan çalışma ve Maruthappu vd. (2014) tarafından AB ülkelerini ve 1981-2010 dönemini kapsayan çalışma ile uyumludur.

Bu çalışmanın bir diğer bulgusu, kamu sağlık harcamasının doğumda beklenen yaşam süresi üzerindeki etkisine ilişskindir. Gerçekleştirilen analizin katsayısı pozitif olup, bu durum iki değişken arasında pozitif ilişki olduğunu göstermektedir. Doğumda beklenen yaşam süresindeki değişimin \%84'ü kamu sağlık harcaması tarafından açıklanmaktadır. Bu bulgu, doğumda beklenen yaşam süresini artırmak için diğer faktörlerin yanında kamu sağlık harcamasının artırılmasına işaret etmektedir. Alanyazında DBYS ile kamu sağlık harcaması arasındaki etki ya da ilişkiyi araştıran çalışmaya rastlanılmamış, genel ya da kişi başı sağlık harcaması ile DBYS değişkenlerini inceleyen çalışmalara ulaşılmıştır. Jaba vd. (2014), Tüylüoğlu ve Tekin (2009) tarafından yapılan çalışmalar kişi başına sağlık harcamasındaki artışın doğumda beklenen yaşam süresini artırdığını ve Bayın (2016) tarafından yapılan çalışma ise $65+$ yaşam beklentisini artırdığını göstermektedir.

Çalışma sonucunda elde edilen bulgular; kamu sağlık harcamasındaki artışın bebek ve anne ölümünde azalmayı, doğumda beklenen yaşam süresinde ise artışı sağladığını göstermektedir. Ancak bu noktada dikkat edilmesi gereken husus hem genel sağlık harcamasının hem de kamu sağlık harcamasının artırılması noktasında verimlilik ve etkililik gibi prensiplerin de mutlaka dikkate alınması gereğidir. Özellikle sağlı hizmetinin doğası gereği verimliliği sağlamanın güç olması nedeniyle harcamaların artırılmasında daha da dikkatli davranılmalıdır. Ayrıca sağlık göstergelerini etkileyen tek faktör kamu sağlık harcamaları değildir. Bu nedenle bu göstergelerde iyileşmeyi sağlamada bu göstergeleri etkileyen sağlık dışı faktörler de dikkate alınmalıdır. Gelecekte gerçekleştirilecek çalışmalarda özel sağlık harcamalarının (özellikle cepten sağlık harcamalarının) sağlık göstergeleri üzerine etkisi incelenebilir. Ayrıca sağlık göstergeleri olarak farklı göstergeler ele alınabileceği gibi farklı ülke grupları (AB ülkeleri, DSÖ üyesi ülkeler gibi) analiz edilebilir. 


\section{KAYNAKÇA}

Ağır, H. ve Tıraş, H. H. (2018), “Türkiye'de Sağlık Harcama Türlerinin Değerlendirilmesi”, Kahramanmaraş Sütçü İmam Üniversitesi Sosyal Bilimler Dergisi, 15(2), s.643-670.

Barenberg, Andrew J., Deepankar B. \& Soylu, C. (2017), “The Effect of Public Health Expenditure on Infant Mortality: Evidence From A Panel of Indian States, 1983-1984 to 2011-2012", The Journal of Development Studies, 53(10), s.1765-1784.

Bayın, G. (2016), "Doğuşta Ve İleri Yaşta Beklenen Yaşam Sürelerine Etki Eden Faktörlerin Belirlenmesi”, Türkiye Aile Hekimliği Dergisi, 20 (3), s.93-103.

Çelik, Y. (2019), Sağlık Ekonomisi. 4. Basım, Siyasal Kitabevi, Ankara.

Jaba, E., Balan, C.B. \& Robu, I. B. (2014), “The Relationship Between Life Expectancy at Birth and Health Expenditures Estimated by a Cross-Country and Time-Series Analysis", Procedia Economics and Finance, 15, s.108-114.

Karagöz, Y. (2014), SPSS 21.1 Uygulamalı Biyoistatistik: Tıp, Eczacılık, Diş Hekimliği ve Sağlık Bilimleri İçin. 1. Basım, Nobel Akademik Yayıncılık Eğitim Danışmanlık Tic. Ltd. Şti., Ankara.

Kiross, G. T., Chojenta, C., Barker, D. \& Loxton, D. (2020), "The Effects of Health Expenditure on Infant Mortality in Sub-Saharan Africa: Evidence from Panel Data Analysis", Health Economics Review, 10(5), s.1-9.

Maruthappu, M., Ng, K.Y.B., Williams, C., Atun, R., Agrawal, P. \& Zeltner, T. (2015), “The Association Between Government Healthcare Spending and Maternal Mortality in the European Union, 1981-2010: A Retrospective Study”, BJOG, 122(9), s.1216-1224.

Nwankwo, C. E. (2018), “The Effects of Public Health Spending on Maternal Mortality in Nigeria", Journal of Economics And Sustainable Development, 9(20), s.141-152.

Sümbüloğlu, K. (1990), Să̆llk Alanına Özel Istatistiksel Yöntemler, 3. Bası, Hatiboğlu Yayınları, Ankara.

Tezcan, S. (2009), Epidemiyoloji: Tıbbi Araştırmaların Yöntem Bilimi, Hacettepe Halk Sağlığı Vakfı Yayın No: 92/1, Ankara.

Tüylüoğlu, Ş. \& Tekin, M. (2009), “Gelir Düzeyi ve Sağlık Harcamalarının Beklenen Yaşam Süresi ve Bebek Ölüm Oranı Üzerindeki Etkileri”, Çukurova Üniversitesi İktisadi ve İdari Bilimler Fakültesi Dergisi, 13(1), s.1-31. 
DICLE ÜNIVERSITESI İKTISADİ VE IDARI BILIMLER FAKÜLTESI DERGISI

Dicle University, Journal of Economics and Administrative Sciences

ISSN: 13094602 / E-ISSN: 2587 - 0106

Yll / Year: 2021

Cilt /Volume: 11

Sayı / Issue: 21

Sayfalar /Pages: 73-84

Sağlık Bakanlı̆̆ı (2019), Să̆glk İstatistikleri Yılll̆̆g 2018, Ankara: Sağlık Bilgi Sistemleri Genel Müdürlüğü, $\quad$ Erişim Linki:

https://dosyasb.saglik.gov.tr/Eklenti/36134,siy2018trpdf.pdf?0, (ET: 15.08.2020). 